\title{
CAPTAÇÃO E USO DE ÁGUAS SUBTERRÂNEAS NO MUNICÍPIO DE ADAMANTINA - SP
}

Marcelo Marconato Prates ${ }^{1}$

\author{
Josiane Lourencetti 2
}

Denilson Burkert ${ }^{3}$

RESUMO: Com o crescente aumento da demanda por água, se torna cada vez mais necessário a implantação de sistemas de gestão que possibilitem a utilização sustentável dos recursos hídricos. Uma importante ferramenta utilizada nesse processo é a outorga de uso da água, instrumento básico de gestão dos recursos hídricos que envolve aspectos técnicos, legais e econômicos. As informações geradas a partir das outorgas podem colaborar para o conhecimento sobre o manancial subterrâneo de maneira a garantir seu uso de forma sustentável e estratégica. $O$ objetivo do trabalho foi analisar o uso da água subterrânea em Adamantina - SP e gerar informações que auxiliem na gestão da explotação do manancial subterrâneo no município. No trabalho utilizou-se de informações de 86 poços que foram processadas nos softwares Surfer e Excel, possibilitando assim a elaboração de mapas temáticos e confeç̧ão de gráficos, para interpretação das informações. Os resultados apontaram o abastecimento público como

\footnotetext{
${ }^{1}$ Pós-graduando FEIS/UNESP: mmp1973@hotmail.com

2 Pós-graduanda FEIS/UNESP: annylouttii88@gmail.com

3 Pesquisador da APTA Regional Alta Paulista: denilsonb@apta.sp.gov.br
} 
principal usuário de água subterrânea no município, captando aproximadamente 10.500 $\mathrm{m}^{3} / \mathrm{d}$ por meio de poços que exploram simultaneamente os aquíferos Bauru e Serra Geral, cujas profundidades apresentam-se relativamente mais elevadas em relação aos poços dos demais usos. Verificou-se também grande quantidade de poços utilizados no meio rural, apontando assim a importância da água subterrânea para esse tipo de usuário.

Palavras-chave: Recursos hídricos. Aquífero Bauru. Aquífero Serra Geral.

\section{INTRODUÇÃO}

Com o constante aumento da demanda pela utilização dos recursos hídricos, a exploração do manancial subterrâneo tem aumentado consideravelmente no mundo. A insustentabilidade da utilização dos mananciais superficiais, considerando o aspecto quantitativo e qualitativo, é o principal fator que contribui para o aumento das captações subterrâneas (HOWARD e GELO, 2003).

No Brasil, segundo a ANA (2012), as maiores vazões retiradas de águas subterrâneas em 2010, referiam-se aos usos consultivos para fins de irrigação, com 1.270 $\mathrm{m}^{3} / \mathrm{s}$ (109,72 milhões de $\left.\mathrm{m}^{3} / \mathrm{dia}\right)$ e para abastecimento urbano, com $522 \mathrm{~m}^{3} / \mathrm{s}(45,1$ milhões de $\mathrm{m}^{3} / \mathrm{dia}$ ), correspondentes a $54 \%$ e $22 \%$ do total, respectivamente.

No Estado de São Paulo, o abastecimento urbano é realizado por captações totalmente subterrâneas em 320 municípios, captações mistas (superficiais e subterrâneas), em 250 municípios e, em 71 municípios, é utilizado o sistema integrado para este uso (ANA, 2013).

Nas UGRHIs (Unidades de Gerenciamento de Recursos Hídricos do Estado de São Paulo) 20 e 21 (Aguapeí e Peixe, respectivamente) há o registro de 3.186 poços que se destinam ao suprimento da demanda por água, destes 283 atendem aos usuários do abastecimento público (CETEC, 2008). Segundo CBH-AP (2013) foi observado, no período de 2007 a 2011, um aumento de 94\% do volume de água subterrânea captada nessas duas UGRHIs, demonstrando o aumento da utilização desses recursos hídricos na região. 
Embora o uso das águas superficiais no meio rural apresente menor custo de extração, muitos produtores preferem a utilização do manancial subterrâneo, pois podem obter a água de forma individualizada (ignorando negociações com outros produtores ou com o governo), como também conseguem maior segurança de produção de água em estações secas (LLAMAS e MARTINEZ-SANTOS, 2005).

Diante da intensificação na utilização dos recursos hídricos visando propiciar o desenvolvimento dos diversos usos, torna-se necessário o controle das captações, de forma a garantir a disponibilidade atual e futura da água.

A elaboração de um plano de gestão para os recursos hídricos subterrâneos é essencial ao estabelecimento da distância ideal entre os poços, do volume máximo de captação e do número de poços por região, almejando evitar o esgotamento do manancial subterrâneo (TODD e MAYS, 2005).

A outorga de direito de uso dos recursos hídricos, um dos cinco instrumentos da PNRH (Política Nacional de Recursos Hídricos), permite o gerenciamento das captações e, ao mesmo tempo, gera condições para a obtenção de informações importantes sobre quantidade e qualidade dos mananciais as quais podem ser armazenadas em sistemas de informações (outro instrumento da $\mathrm{PNRH}$ ) e utilizadas por órgãos gestores com esse propósito.

\section{OBJETIVO}

O trabalho foi elaborado com o objetivo de se produzir informações importantes à gestão de águas subterrâneas em Adamantina - SP, assim como, o perfil estrutural e os usos da água provenientes de poços, estimativa da quantidade de água subterrânea retirada, apontamento dos principais usuários e, avaliação da profundidade e da produtividade dos poços em operação.

\section{METODOLOGIA}

\section{1 ÁREA DE ESTUDO}


O município de Adamantina - SP está situado entre as coordenadas $20^{\circ} 41^{\prime} 07^{\prime \prime}$ de latitude Sul e $51^{\circ} 04^{\prime} 21^{\prime \prime}$ de longitude Oeste. Ocupa uma área territorial de $411 \mathrm{~km}^{2}$, com uma população de 33.797 habitantes (IBGE, 2013).

O fornecimento de água aos usuários do abastecimento público provém exclusivamente de fonte subterrânea, explorando os aquíferos Bauru e Serra Geral.

$\mathrm{Na}$ região urbana e periurbana se concentram a maioria dos poços utilizados para o abastecimento de água do município. Devido a essa peculiaridade foram delimitadas 5 sub-bacias hidrográficas de forma a melhor caracterizar a região estudada (Figura 1).

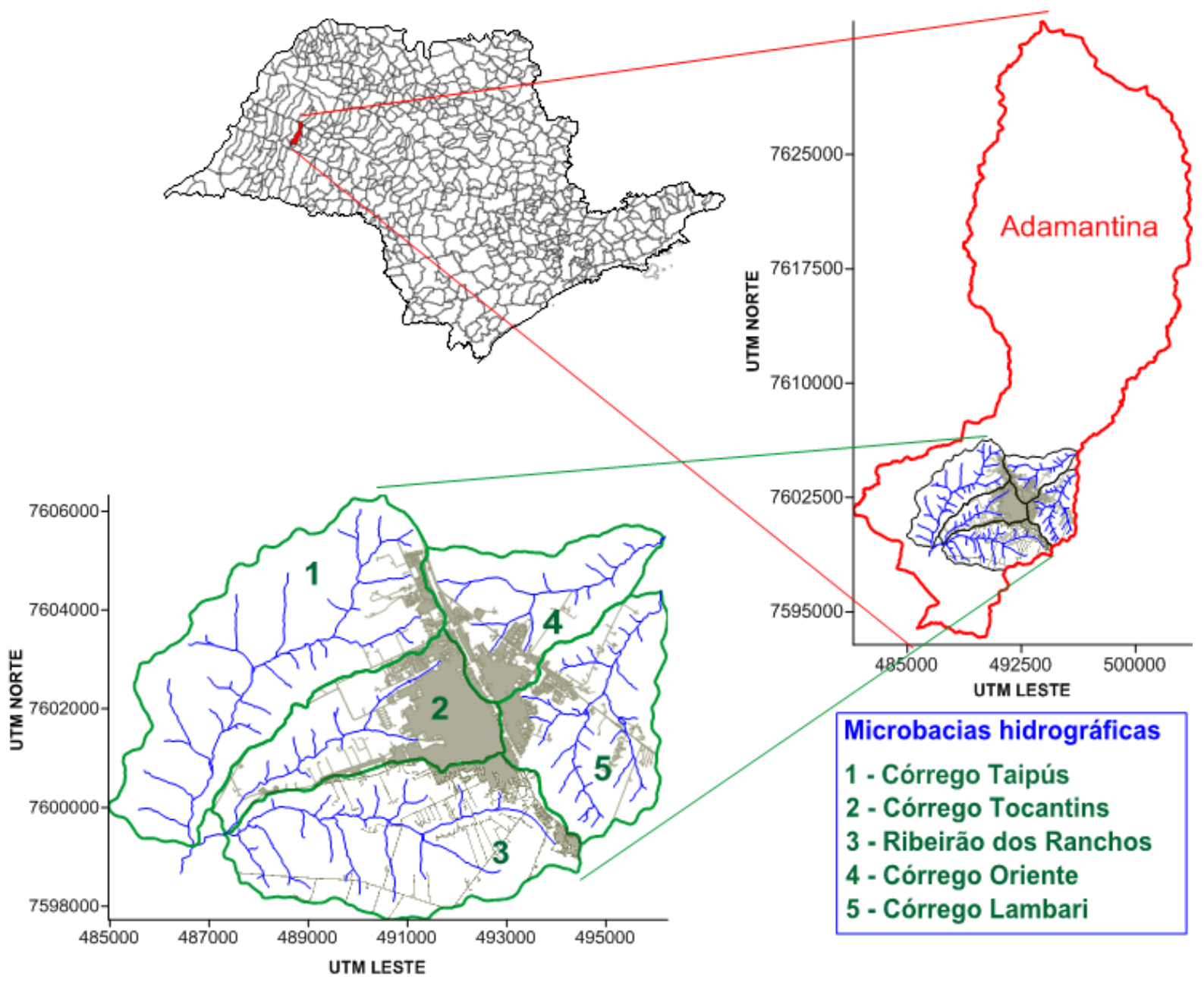

Figura 1 - Localização da área de estudo, município de Adamantina - SP. 


\subsection{CONSTRUÇÃO DOS MAPAS E BASE DE DADOS VETORIAIS UTILIZADA}

Imagem de satélite datada de 14/09/2011 produzida pelo software Google Earth foi utilizada como base de dados vetoriais para a construção dos mapas. Utilizando-se de ferramentas do software, foram digitalizados os contornos das microbacias hidrográficas, da área urbana e periurbana do município de Adamantina e, as linhas dos cursos d'água principais e seus afluentes (Figura 2).
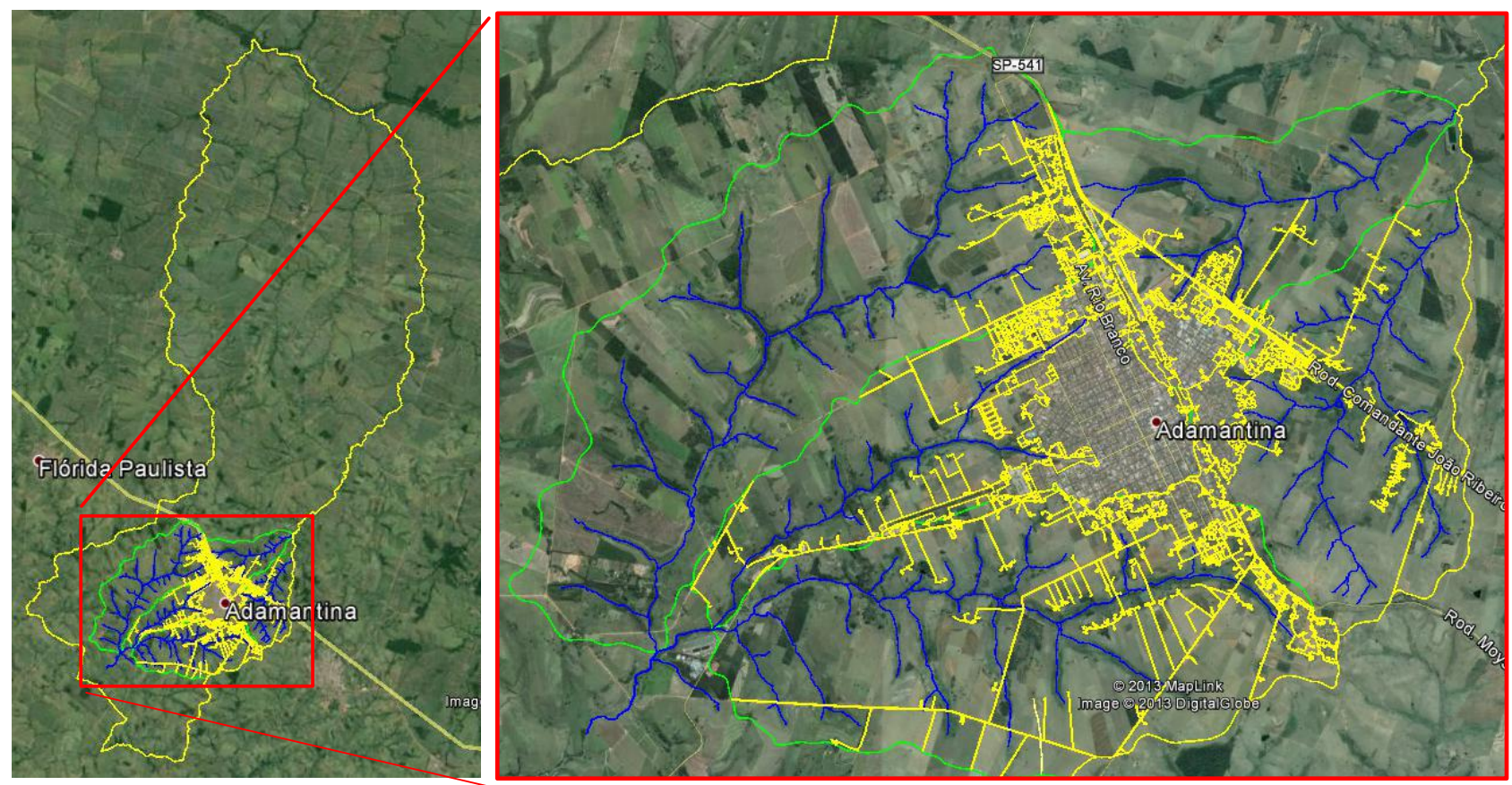

Figura 2 - Arquivo vetorial digitalizado sobre imagem de satélite do Google Earth. As linhas em azul representam os corpos d' água, em amarelo a malha urbana e em verde as microbacias no município de Adamantina - SP.

Após a digitalização, os arquivos vetoriais foram exportados em extensão compatível com o software Spring 5.1.8 (kml), no qual os arquivos foram transformados em extensão reconhecível pelo Surfer 10 (dxf) e, neste último foram processados os mapas. 


\subsection{AVALIAÇÃO DO USO DA ÁGUA}

O estudo foi realizado por meio de coleta de informações de poços outorgados no município de Adamantina, as quais foram processadas nos softwares Microsoft Excel e Surfer 10 , tendo como finalidade a elaboração de gráficos e mapas temáticos para avaliação do uso da água subterrânea.

As informações dos poços cadastrados no município foram obtidas por meio consulta a bancos de dados disponíveis nos escritórios do DAEE (Departamento de Água e Energia Elétrica) de Marília e de Presidente Prudente e pelo SIAGAS (Sistema de Informações de Águas Subterrâneas).

No estudo foram utilizados 86 poços para identificação dos tipos de uso da água subterrânea e vazão explotada no município, sendo que para a interpolação dos valores da vazão específica, que representa a produção dos poços, foram utilizados 54 , pois nem todos traziam a informação desta variável.

Foram realizadas visitas em 10 propriedades rurais e em dois estabelecimentos comerciais na área urbana de Adamantina, onde existem poços tubulares captando água do Aquífero Bauru, sendo coletadas informações destes a fim de obter dados complementares ao trabalho. A identificação das propriedades foi preservada em razão dos poços não estarem legalizados.

Assim, dos 86 poços utilizados, 74 estavam cadastrados nos bancos de dados do DAEE e SIAGAS e 12 não possuíam registro. Informações do período de bombeamento dos poços não cadastrados foram fornecidas pelos proprietários ou responsável no local. Nos casos onde o proprietário não tinha a informação sobre a vazão de estabilização e/ou rebaixamento do nível da água, foi realizado teste no local.

Quanto ao tipo de usuário, os poços foram categorizados em quatro classes de uso: industrial, público, rural e urbano. A categoria "público" abrangeu as perfurações destinadas ao abastecimento público do município, ou seja, poços da Sabesp (Companhia de Saneamento Básico do Estado de São Paulo). No uso rural foram selecionados os poços localizados em sítios e chácaras. O uso industrial foi representado por indústrias localizadas na área urbana e rural, como curtumes, fábrica de biscoitos e 
usina de açúcar e álcool. No uso urbano se encontram poços de estabelecimentos comerciais, instituições públicas e privadas, localizados na área urbana do município.

$\mathrm{Na}$ análise de profundidade utilizou-se 73 poços, pois 13 não traziam essa informação, sendo realizada divisão em quatro classes de profundidade para os poços com a informação da variável.

$\mathrm{Na}$ identificação da vazão explotada em Adamantina, para os poços que não traziam a informação da vazão de estabilização, foi atribuído o valor considerando a média de cada tipo de uso. O mesmo critério foi usado para a análise do período de funcionamento do poço. Com os valores da vazão de estabilização e o tempo de bombeamento, foi estimada a vazão diária explotada.

\section{RESULTADOS e DISCUSSÃO}

No município de Adamantina - SP, o maior usuário de água subterrânea, considerando o volume de água explotado, é o abastecimento público com $78 \%$ do total ou $10.519 \mathrm{~m}^{3} / \mathrm{d}$, seguido pelo uso urbano com $1.255 \mathrm{~m} / \mathrm{d}$ e pelo industrial com $1.218 \mathrm{~m}^{3} / \mathrm{d}$ ambos representando $9 \%$ e, com menor percentagem o uso rural com uma vazão de explotação de $882 \mathrm{~m} 3 / \mathrm{d}$ ou $7 \%$ (Figura 3).

Das 74 perfurações cadastradas no município de Adamantina, 13 explotam águas do Aquífero Serra Geral e Bauru simultaneamente e 61 somente do Aquífero Bauru, assim como os 12 poços não cadastrados.

De acordo com CETESB (2013) o Aquífero Bauru é constituído por rochas sedimentares do Grupo Bauru e Grupo Caiuá, e ocorre de forma extensiva e contínua em todo o Planalto Ocidental do Estado de São Paulo, ocupando um pouco mais de $40 \%$ da área do Estado e daí sua grande importância como manancial. Enquanto que o Aquífero Serra Geral é formado por rochas bastante impermeáveis originadas por derrames basálticos da Formação Serra Geral e intrusões diabásicas, dessa forma, a produção de águas subterrâneas ocorre somente ao longo de falhas e fraturas das rochas e intercalação com rochas mais permeáveis. Os basaltos afloram numa extensão de cerca 
de $20.000 \mathrm{~km}^{2}$, estendendo-se por toda a região Oeste e Central do Estado localizada em camadas inferiores aos sedimentos do Grupo Bauru.

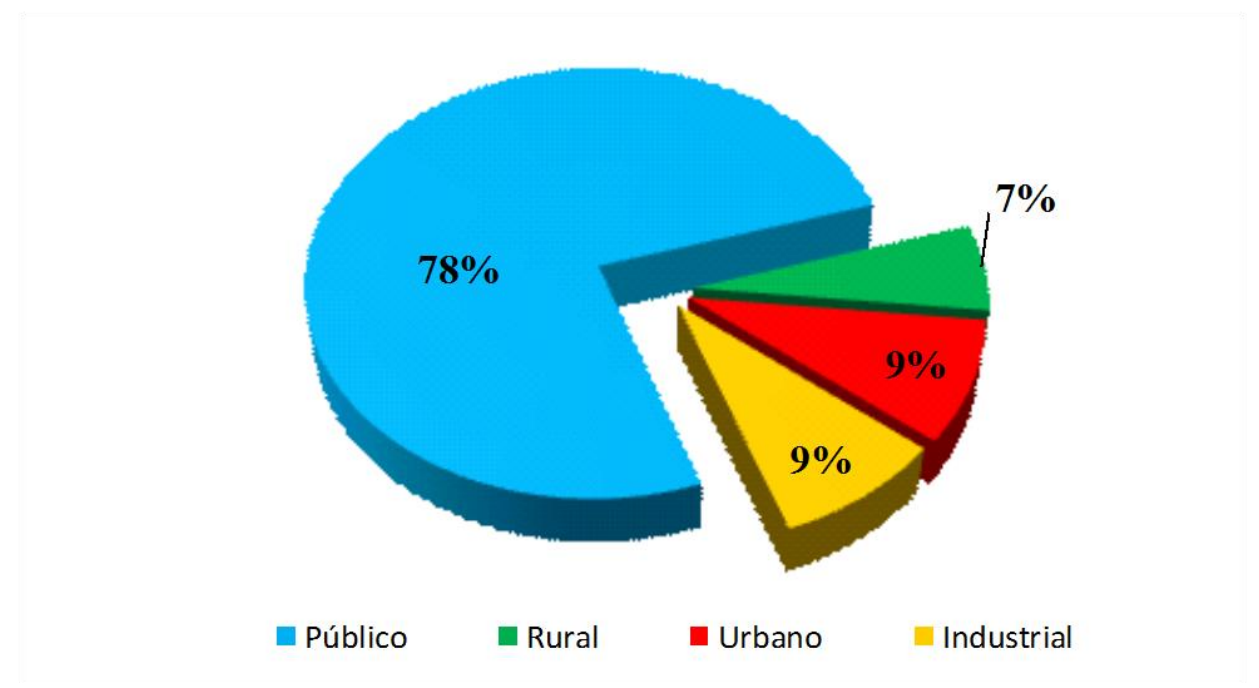

Figura 3 - Usuários da água subterrânea no município de Adamantina - SP.

A maior parte dos poços em Adamantina captam vazões na faixa de 11 a $50 \mathrm{~m} 3 / \mathrm{d}$, conforme 32 registros encontrados, sendo que as perfurações que captam acima de $1.000 \mathrm{~m}^{3} / \mathrm{d}$ se destinam exclusivamente ao abastecimento público do município por meio de 5 poços (Figura 4).

Dos 4 poços restantes utilizados para o abastecimento público, 3 captam uma vazão diária na faixa de 600 a $900 \mathrm{~m}^{3} / \mathrm{d}$ e 1 capta à $30 \mathrm{~m} 3 / \mathrm{d}$, o qual é utilizado para o abastecimento do bairro Lagoa Seca, distante aproximadamente $18 \mathrm{~km}$ da área urbana, ao norte.

Quanto aos poços não cadastrados, 11 captam na faixa de 11 a $50 \mathrm{~m}^{3} / \mathrm{dia}$ e 1 na faixa de até $10 \mathrm{~m}^{3} / \mathrm{dia}$.

Conforme pode ser observado na Figura 4, nas duas classes de menor vazão explotada, se concentram os poços categorizados nos usos rural e urbano. Percebe-se também que os poços com maior vazão estão distribuídos fora da área urbana, dos quais 8 são utilizados para o abastecimento público e 2 para o uso industrial. 
Outro detalhe também percebido é que os poços utilizados para o abastecimento público estão localizados próximos das calhas dos cursos d'água, locais para onde o fluxo da água converge.

Tais localizações podem ter influência na maior produtividade desses poços, principalmente a do poço sob as coordenadas 488600-E; 7603350-N, em que um rebaixamento do nível potenciométrico em torno de $3,3 \mathrm{~m}$ produz vazão de $45 \mathrm{~m} 3 / \mathrm{h}$.

Grande importância também tem o manancial subterrâneo para o suprimento de água de várias propriedades rurais, existindo grande quantidade de poços para esta finalidade, $50 \%$ do total das perfurações no município, utilizadas no trabalho. 

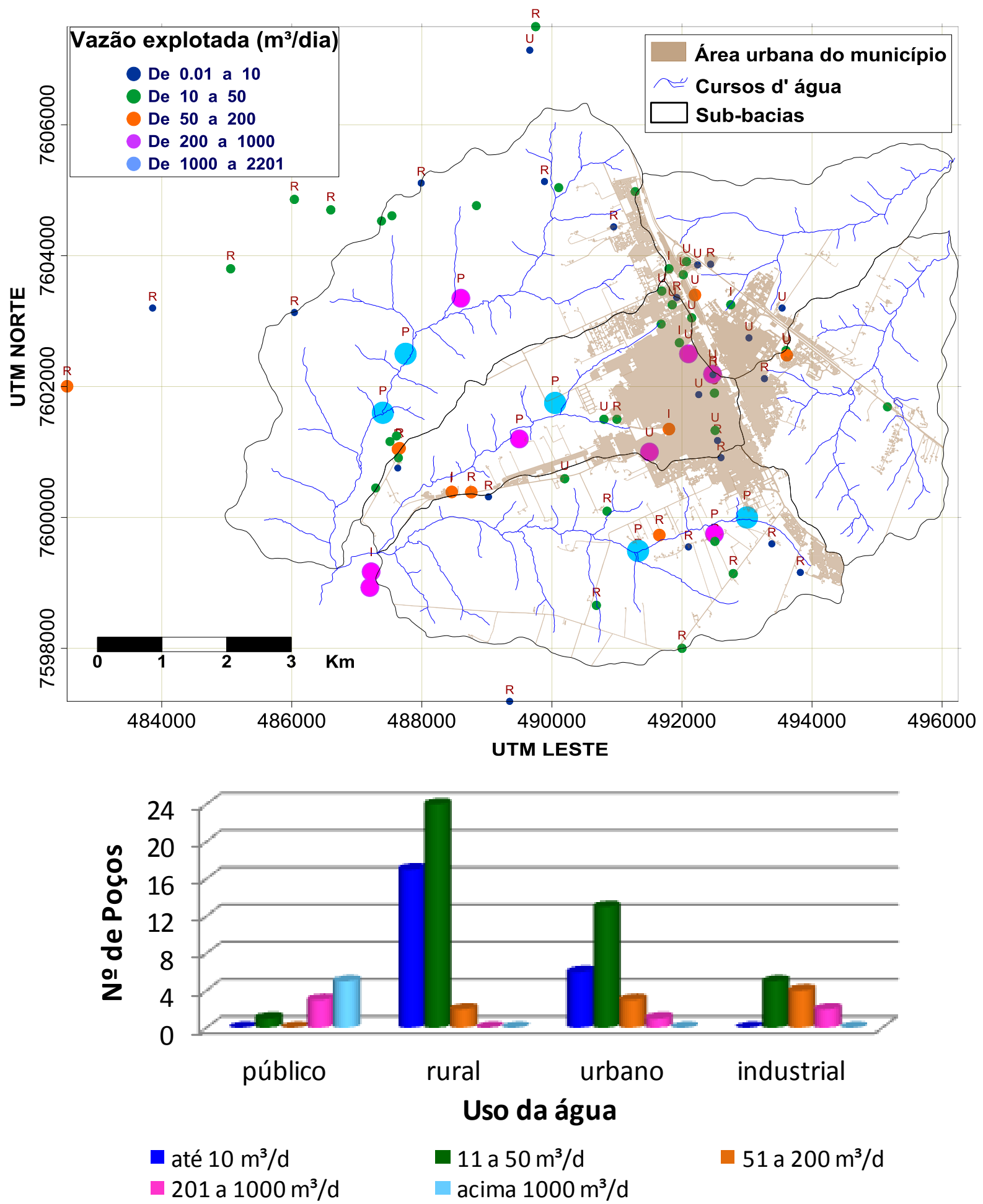

Figura 4 - Vazão diária explotada de poços no município de Adamantina de acordo com o tipo de usuário, com ilustração da quantidade e distribuição dos poços na área estudada 
São observados 37 poços com profundidades de perfurações na faixa de 81 a 150 $\mathrm{m}$, sendo que no uso público o maior número de perfurações se encontra na faixa acima de $200 \mathrm{~m}$ (Figura 5).

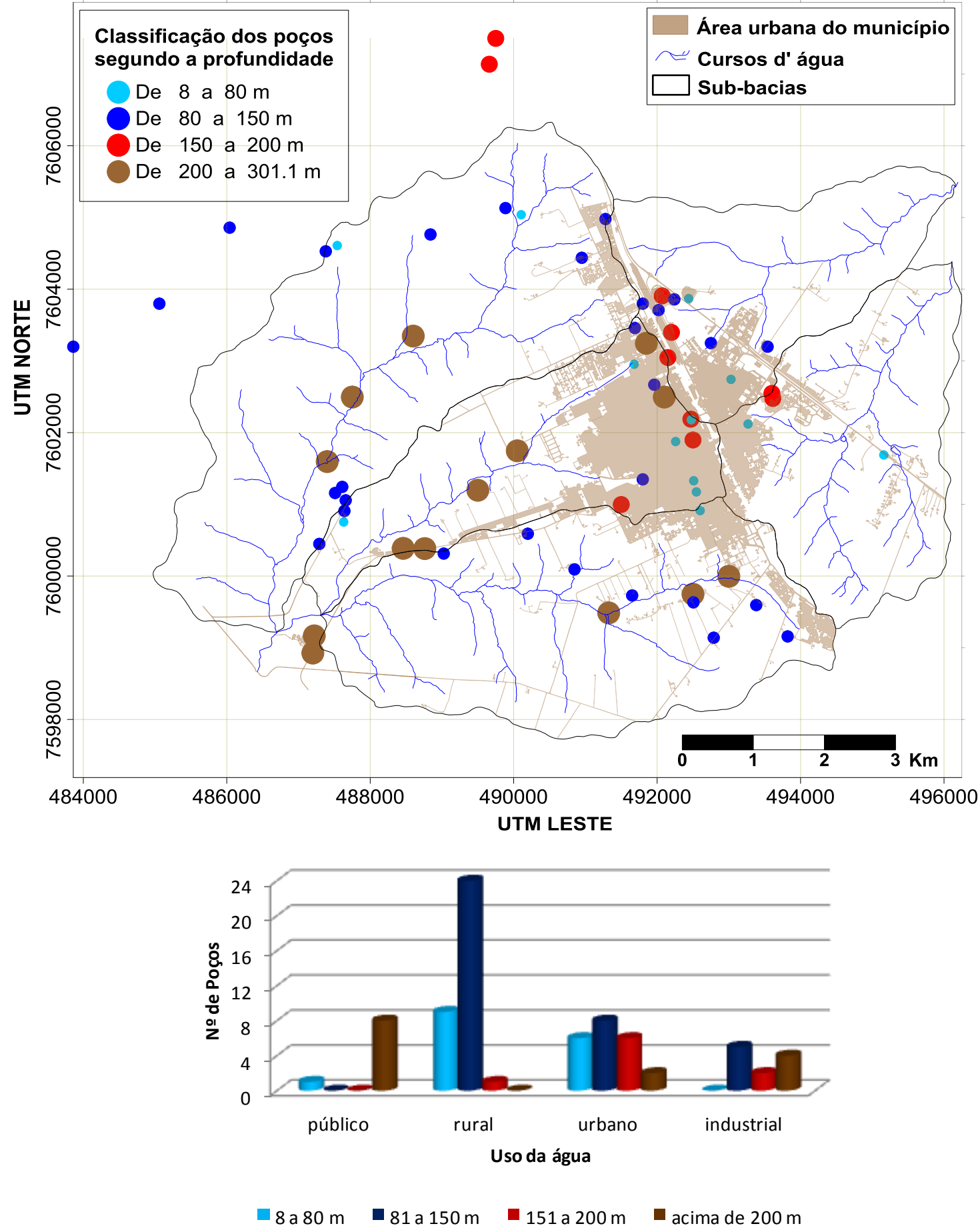

Figura 5 - Profundidade dos poços em Adamantina - SP. 
Conforme os 13 registros encontrados indicando a explotação simultaneamente nos aquíferos Serra Geral e Bauru, nota-se que as profundidades destes poços se encontram na faixa acima de 200 metros.

O abastecimento público busca profundidades mais elevadas em decorrência da maior vazão demandada. Maiores vazões em regiões cuja produtividade dos poços são relativamente baixas podem ser obtidas por um maior rebaixamento do nível potenciométrico do aquífero, que em termos técnicos representa a diferença entre o nível estático e o nível dinâmico (Figura 6). Já em regiões onde a produtividade é maior, com menor rebaixamento do nível potenciométrico ainda se obtém vazões consideráveis. Tais estratégias permitem a retirada de água em condições de menor vulnerabilidade permitindo o uso do recurso hídrico mesmo com o aumento da expansão urbana no município em um futuro próximo.

$\mathrm{Na}$ Figura 6 são mostrados perfis construtivos de dois poços da SABESP que explotam simultaneamente os aquíferos Bauru e Serra Geral, onde pode ser percebida essa diferença de produtividade entre regiões distintas. 
Coordenada UTM

493000-E 7600000-N

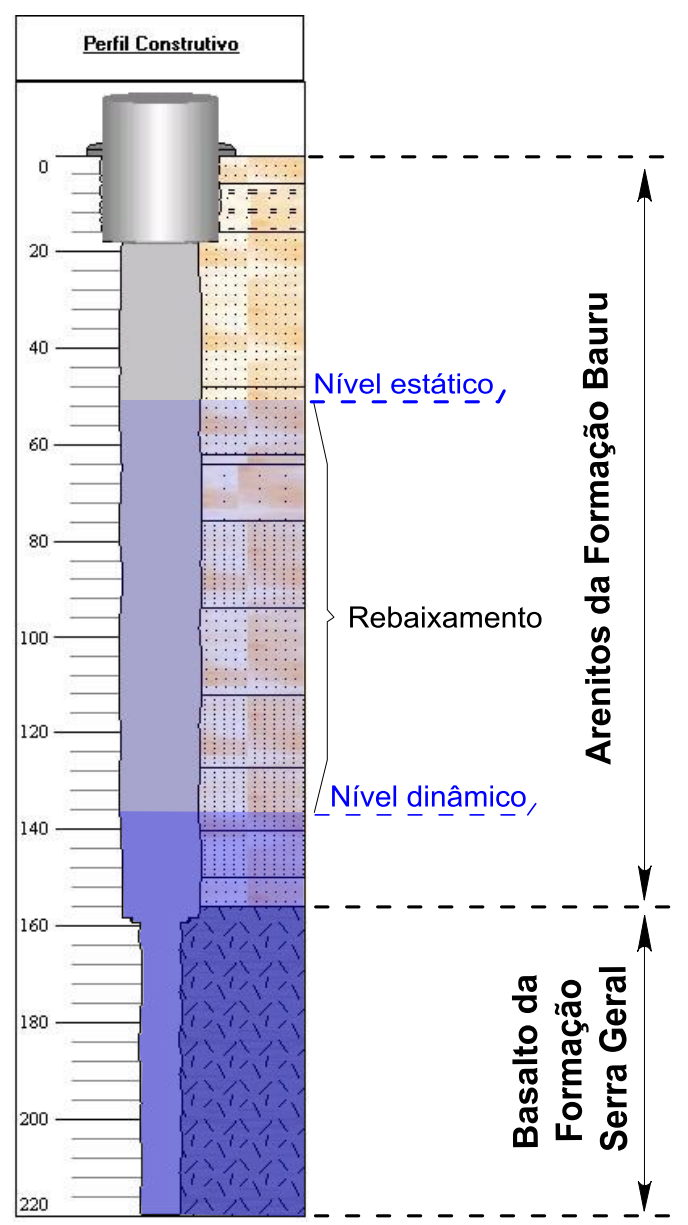

Coordenada UTM

493000-E 7600000-N

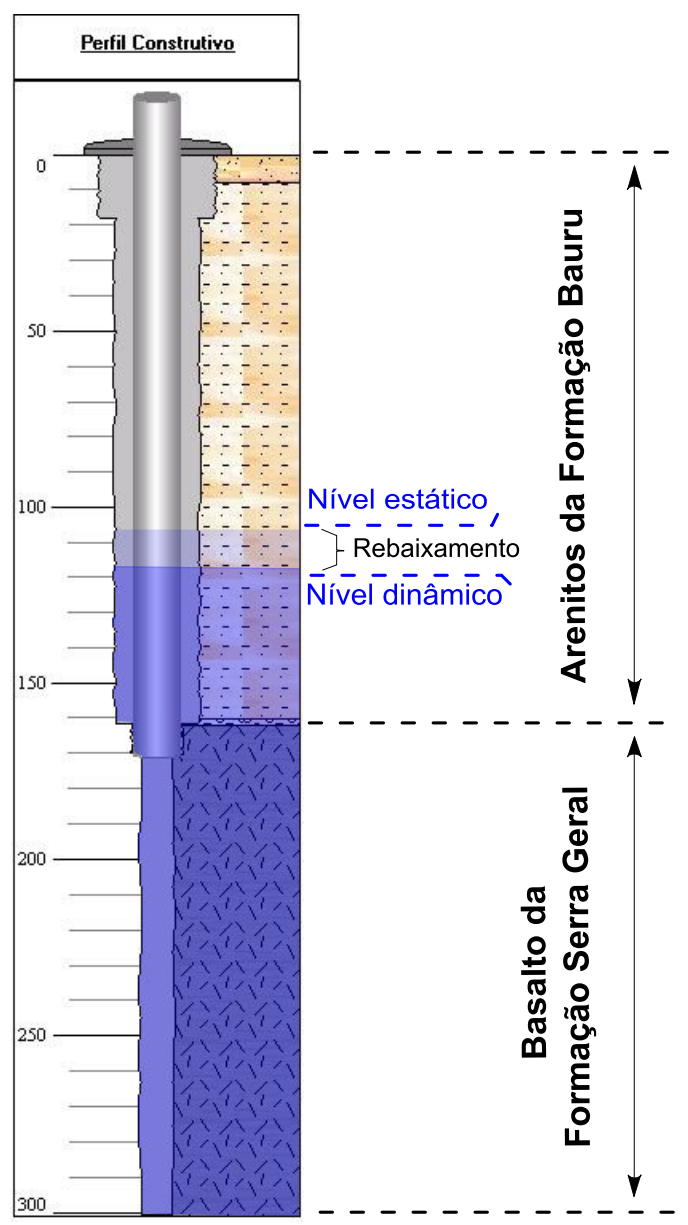

Figura 6 - Perfis construtivos de dois poços da SABESP, ilustrando o rebaixamento do nível potenciométrico. Adaptado de SIAGAS (2013).

No poço à esquerda para se obter a vazão de estabilização, ou seja, vazão a partir da qual o aquífero não apresenta mais rebaixamento significativo do nível potenciométrico, é necessário um rebaixamento de aproximadamente $84 \mathrm{~m}$ para a vazão de $30 \mathrm{~m}^{3} / \mathrm{h}$. No poço à direita, se obtém a vazão de estabilização de $80 \mathrm{~m}^{3} / \mathrm{h}$ com rebaixamento de aproximadamente $12 \mathrm{~m}$ do nível potenciométrico.

As maiores produtividades foram encontradas em poços no município que explotam simultaneamente nos aquíferos Bauru e Serra Geral, porém em alguns poços que explotam exclusivamente o Aquífero Bauru puderam ser encontradas vazões específicas consideráveis (Figura 7). 
A partir da interpolação dos valores das vazões específicas, encontrados nos 42 poços cadastrados e nos 12 sem cadastro, que explotam o Aquífero Bauru, foi construído o mapa de isovalores desta variável (Figura 7).

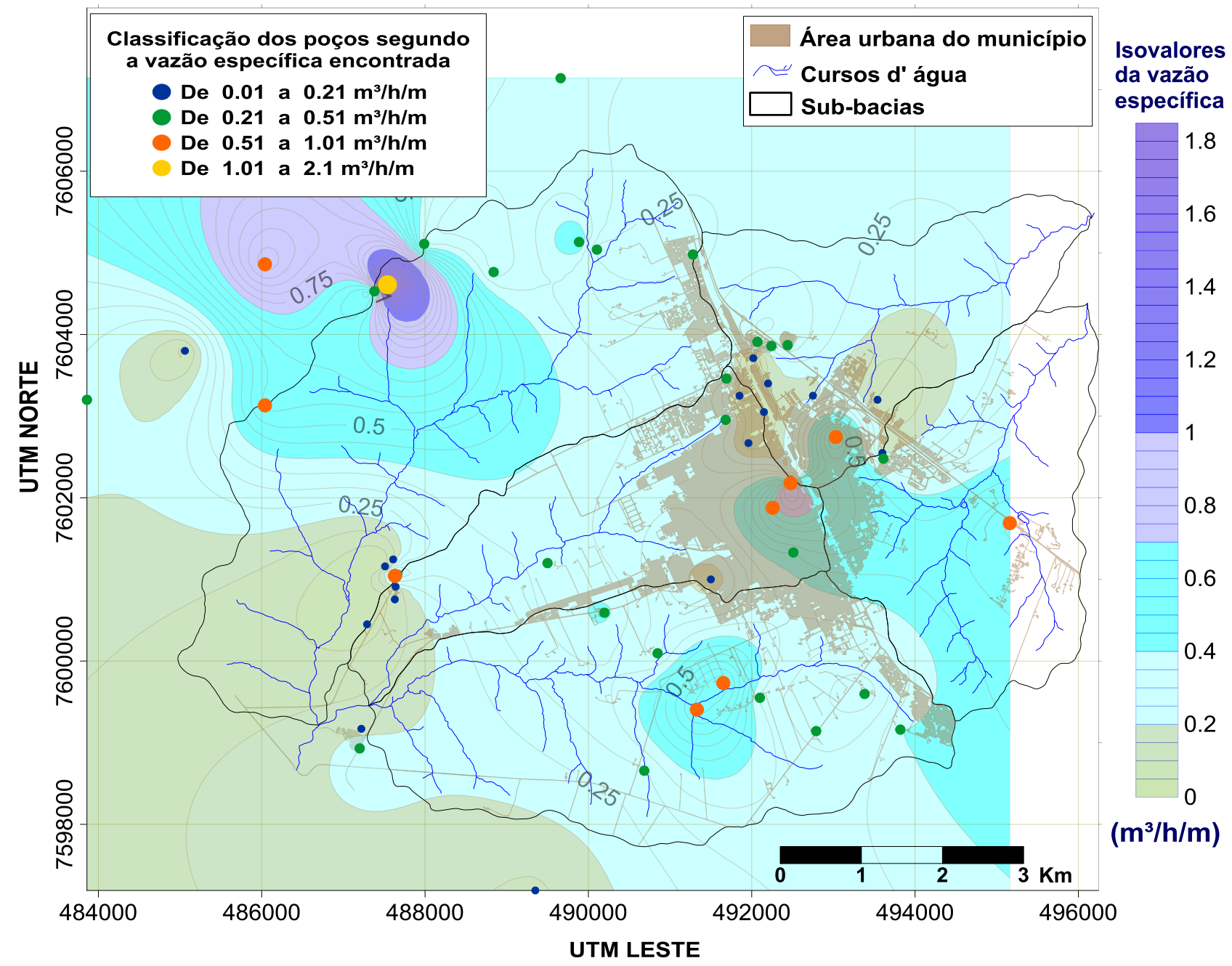

Figura 7 - Mapa de isovalores de vazão específica do Aquífero Bauru na região das sub-bacias estudadas no município de Adamantina - SP, com a distribuição dos poços utilizados na interpolação.

Pode ser observado que a produtividade dos poços não se distribui homogeneamente sobre a área de estudo. Este fato pode ser explicado por razões como os diferentes materiais geológicos que compõem a estrutura do aquífero e a morfologia do relevo, que permite que o fluxo da água seja direcionado para as partes mais baixas das bacias hidrográficas. 
Com exceção a três poços localizados na parte central da área urbanizada, cuja vazão específica varia entre 0,5 a $1 \mathrm{~m} 3 / \mathrm{h} / \mathrm{m}$, pode ser percebido que nas partes mais elevadas, ou seja, nos divisores topográficos, a produtividade dos poços é menor. Estes três correspondem a poços comuns, também conhecidos por cacimbas, em que as profundidades são relativamente baixas, em torno de 8 a 20 metros.

Portanto a região com maior valor da vazão específica interpolada na parte central da cidade tem influência desses três poços rasos, podendo não traduzir a real situação da produtividade do aquífero neste local, tendo em vista que além de pouco profundos, esses poços possuem diâmetro superior aos poços tubulares. Além disso, foi verificado que o equipamento de bombeamento instalado capta água em baixas vazões, em torno de 1,5 $m^{3} / h$.

As vazões específicas encontradas nos poços perfurados na região estudada, em sua maior parte, ocorrem de acordo com os valores descritos por São Paulo - CERH (2005), em que ocorre a predominância de vazões específicas de até $0,5 \mathrm{~m} 3 / \mathrm{h} / \mathrm{m}$ no Aquífero Bauru, cujas espessuras saturadas estão na faixa de 100 a $150 \mathrm{~m}$.

Não se realizou a interpolação dos valores da vazão específica do Aquífero Serra Geral, pois a maior parte dos poços que penetram esta formação capta água simultaneamente deste e do Aquífero Bauru, o que poderia influenciar no resultado apresentado. Assim os poços que explotam no Serra Geral não foram utilizados na interpolação e não estão descritos na Figura 7.

Durante visita de campo, verificou-se a existência de propriedades rurais e urbanas que utilizam o manancial subterrâneo, mas que não possuem autorização junto ao órgão responsável. Desta forma não é possível o controle em termos quantitativos e qualitativos da água explotada, a qual além de atender a demanda gerada pelos diferentes usos, também deve apresentar características de qualidade que a tornem apta ao consumo.

A qualidade de água do Aquífero Bauru tem sido pesquisada nos últimos anos devido ao seu potencial de contaminação por nitrato (VARNIER et al., 2010). De acordo com esses autores é necessário um controle e fiscalização para evitar poços mal construídos e/ou mal conservados, que possam carrear a contaminação para unidades hidrogeológicas mais profundas. 
Devido ao fato de Adamantina não possuir quantidade tão expressiva de poços em relação a alguns municípios paulistas que já apresentam problemas de superexplotação conforme SMA (2010), o Aquífero Bauru, atualmente, representa uma fonte segura para o abastecimento de água do município, porém atenção deve ser dispensada às normas técnicas e legais quando da utilização deste manancial.

A regularização dos poços, como por exemplo, com a geração das respectivas outorgas do uso da água, pode garantir com que as exigências em termos estruturais sejam atendidas de maneira que se evite a contaminação, mas também para que se faça o uso dos aquíferos de maneira mais coerente com sua capacidade de recarga da água.

\section{CONCLUSÕES}

De acordo com os resultados obtidos constata-se que o usuário que mais utiliza água subterrânea em Adamantina é o abastecimento público, o qual explota águas dos aquíferos Bauru e Serra Geral por meio de 9 poços da SABESP.

Os poços que apresentam a maior produtividade destinam-se ao suprimento da demanda do abastecimento público, os quais foram perfurados em profundidades em torno de 300 metros, estrategicamente próximos às calhas dos cursos d'água, afastados da área urbanizada, evitando-se dessa maneira a proximidade com fontes poluidoras e a competição com outros usuários do mesmo recurso hídrico.

A captação de águas subterrâneas de forma irregular representa a necessidade da adequação dessa situação de forma a evitar-se problemas futuros em termos de contaminação e o uso descontrolado das águas subterrâneas no município.

\section{REFERÊNCIAS}

ANA - Agência Nacional das Águas. Atlas Brasil: abastecimento urbano de água: resultados por $\quad$ município.
$<$ http://atlas.ana.gov.br/Atlas/forms/Home.aspx>. Acesso em 10 set. 2013.

ANA - Agência Nacional das Águas. Conjuntura dos recursos hídricos no Brasil: informe 2012. Ed. Especial. Brasília: ANA, 215 p., 2012. 
CBH-AP - Comitê das Bacias Hidrográficas dos Rios Aguapeí e Peixe. Relatório de Situação dos Recursos Hídricos 2012 (Ano Base: 2011) - UGRHI 20 e 21. Marília, 109 p., 2013.

CETESB - Companhia de Tecnologia de Saneamento Ambiental. Águas Subterrâneas. Disponível em: <http://www.cetesb.sp.gov.br/agua/qualidade-da-agua-subterranea/11bauru>. Acesso em 10 set. 2013.

CETEC - Centro Tecnológico da Fundação Paulista de tecnologia e Educação. Plano das Bacias Hidrográficas dos Rios Aguapeí e Peixe. Unidade de Gerenciamento de Recursos Hídricos - UGRHIs - 20/21. Estado de São Paulo, 2008. 335 p., 2008.

SÃO PAULO - CERH - Conselho Estadual de Recursos Hídricos. Mapa de águas subterrâneas do Estado de São Paulo: escala 1:1.000.000:nota explicativa. São Paulo: DAEE:IG:IPT:CPRM, 2005.

HOWARD, K. W. F.; GELO, K. K. Intensive groundwater use in urban areas: the case of megacities. In: LLHAMAS, R.; CUSTÓDIO, E. Intensive groundwater use: Challenges and Opportunities. Lisse: A. A. Balkema Publishers, p.35-58, 2003.

IBGE - Instituto Brasileiro de Geografia e Estatística. Disponível em: <http://www.ibge.gov.br/home/>. Acesso em: 15 set. 2013.

LLAMAS, M. R.; MARTINEZ-SANTOS, P. Intensive groundwater use: silent revolution and potential source of social conflicts. Journal of Water Resources Planning and Management, Spain, p.337-342, 2005.

SMA - Secretaria do Meio Ambiente. Resolução ํㅜ 14, de 05 de março de 2010. Define as diretrizes técnicas para o licenciamento de empreendimentos em áreas potencialmente críticas para a utilização de águas subterrâneas. Diário Oficial, São Paulo, 2010. Disponível em:<http://www.ambiente.sp.gov.br >. Acesso em: 23 set. 2013.

TODD, D. K.; MAYS, L. W. Groundwater Hydrology. 3 ed. Hoboken: John Wiley \& Sons, Inc., 636 p., 2005.

VARNIER, C.; IRITANI, M.A.; VIOTTI, M.; ODA, G.H.; FERREIRA, L.M.R. Nitrato nas águas subterrâneas do sistema aquífero Bauru, área urbana do município de Marília (SP). Revista do Instituto Geológico, São Paulo, 31 (1/2), 1-21, 2010. 